\title{
23153 室マイクロ空圧ワブルモータの開発
}

\author{
Development of three-chamber micro pneumatic wobble motor
}

\author{
$\bigcirc$ 岡本 清秀（岡山大） 正 鈴森 康一（岡山大） 正 神田 岳文（岡山大） \\ 山田 嘉昭（(財）岡山県産業振興財団）
}
Kiyohide OKAMOTO, Okayama University, 3-1-1, Tsushima-naka, Okayama Koichi SUZUMORI, Okayama University Takefumi KANDA, Okayama University Yoshiaki YAMADA, Okayama Prefecture Industrial Promotion Foundation

The development of miniature high torque motors is essential for the realization of miniature robots which require large driving force. This is the background of this research to develop pneumatic wobble motor, which is high torque stepping motor with reduction function.

Pneumatic wobble motor consists of a donut-shaped wobble generator, which is made of silicone rubber, a wobble ring, which is made of metal, and a rotor. The rotor is encased in the wobble ring, which is covered by the wobble generator. The wobble generator has three chambers and injecting air rotate.

Authors had developed a six-chamber $\phi 10 \mathrm{~mm}$ pneumatic wobble motor and six-chamber $6.7 \mathrm{~mm}$. In this study, the pneumatic wobble motor is miniaturized to $\phi 6 \mathrm{~mm}$ by applying fine processing technology. Besides the number of pneumatic chambers are decreased from 6 to 3 .

\section{1. 緒言}

近年, 介護，医療，狭險部点検，さまざまな分野にロボッ 卜を応用しようという試みが活発に進められている。これに 伴い,アクチュエータに対する期待は, 例えば, 小型軽量, 信頼性，柔らかさなど多様化し，従来の電磁モータ以外の新 しい原理に基づくアクチュエータの実現が模索されている.

これまで，筆者らは空圧ワブルモータと呼ぶ新しいモータ 構造を考案し, 6 空 $\phi 10 \mathrm{~mm}$ タや 6 室 $\phi 6.7 \mathrm{~mm}$ モータの開 発に成功した[1][2]. これは簡単構造, 軽量といった従来の空 気圧アクチュエータの特徵を生かしたまま, 分解能の高いス テッピング動作を行う新しい空圧モータである.

本研究では, 微細加工技術の適用により $\phi 6 \mathrm{~mm}$ の小型化を 実現するとともに，ハーフピッチ駆動によって圧力室を 6 室 から 3 室にすることに成功した.

\section{2. 空圧ワブルモータの構造と駆動原理}

\section{1 動作原理}

図 1 にワブルモータの駆動原理を示す. 円筒状部材 A と円 柱状部材 B があり, 部材 $\mathrm{A}$ の内面を部材 $\mathrm{B}$ が滑らずに転がっ ているのが分かる.これを利用したものが，ワブルモータの 原理である. ワブルモータにおいてワブルリングが部材 A の 役割を，ロータが部材 B の役割を果たし減速機能を有してい る。

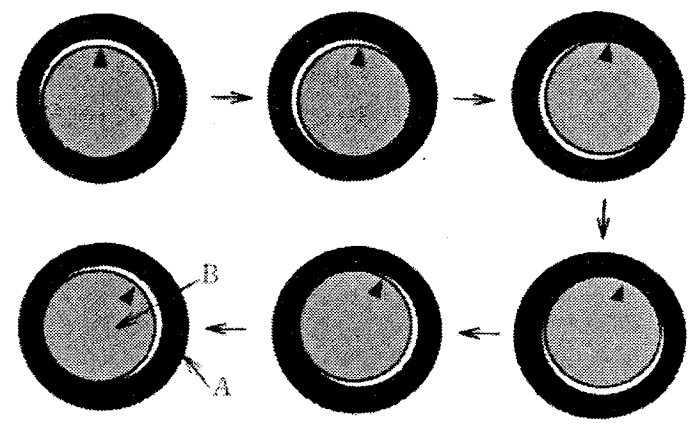

Fig.1 Driving principle of wobble motor

\section{2 空圧ワブルモータの構造}

図 2 に，今回製作したマイクロ空圧ワブルモータの断面図 を示す. ワブルモータは主に,

(1) シリコーンゴム製のワブルジェネレータ

(wobble generator)(図 3 に示す),

(2) 内歯車を持つワブルリング

(wobble ring)(図 4 に示す),

(3) 外歯車を持つロー夕

(rotor)(図 4 に示す)

の 3 点から構成される.

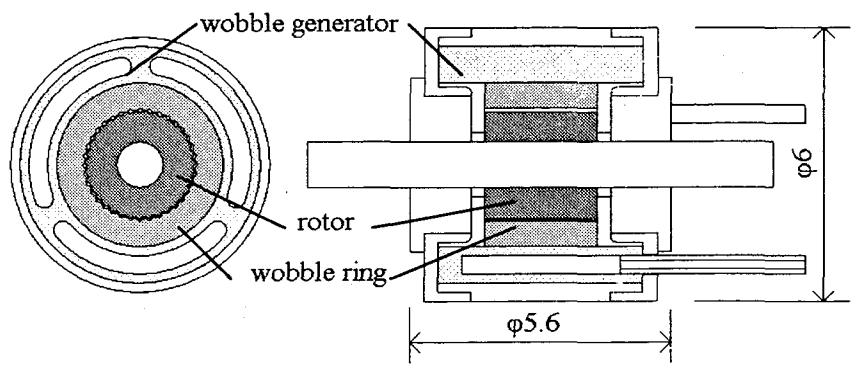

Fig.2 Structure of wobble motor

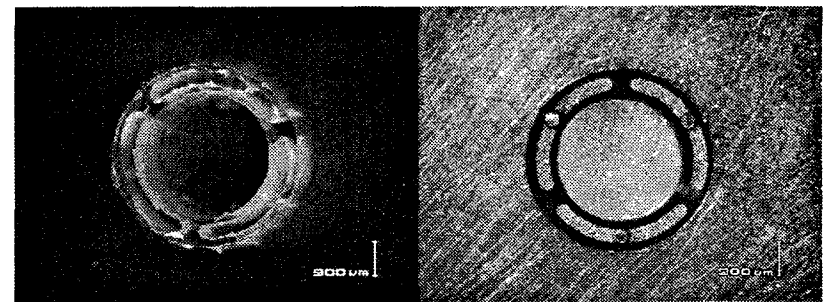

Fig.3 Wobble generator and its metal mold

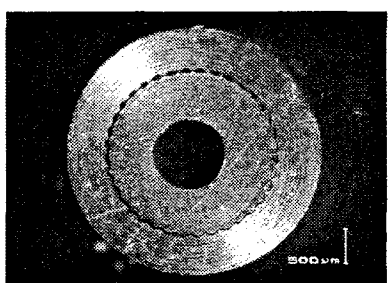

Fig.4 Wobble ring and rotor

日本機械学会 [No.06-6]第 6 回機素潤滑設計部門講演会講演論文集 ['06-5-29,30,松島] 
ロータには外歯車が，ワブルリングには内歯車が形成され ている。また，ワブルジェネレータは内部に 3 個の圧力室を 有している(図 3 に示す).

ワブルジェネレータの内面とワブルリングの外面は密着し ており，ワブルリングは自転しない。このためワブルジェネ レータの各圧力室を順に加圧すると，ワブルリングが公転運 動を行い，歯がかみ合いながらロータが自転を行う。このと き，ロータの歯数をワブルリングの歯数に対して 1 枚少なく 構成しているため，ワブルリングが 1 公転するたびにロータ が 1 歯数分回転する.

\section{3. 許容トルクの理論特性}

図 5 では，本モータの特性解析を説明する。この図におい て点 $\mathrm{C}, \mathrm{O}_{\mathrm{w}}, \mathrm{O}_{\mathrm{r}}$ はそれぞれ, ワブルリングとロータの接触点, ワブルリングの中心，ロータの回転中心である、また，ワブ ルリングの内歯車, およびロータの外歯車のピッチ円竍径を それぞれ， $r_{w}, r_{r}$ とする.

ワブルリングは，ワブルジェネレータからカ $P$ と点 $\mathrm{O}_{\mathrm{v}}$ 周 りのトルク $T_{g}$ 受ける. カ $P$ はワブルジェネレータ内の圧力室 の加圧によって生じる力で，加圧した圧力室の中心点 $\mathrm{A}$ に働 $<$, 点 $\mathrm{O}_{\mathrm{w}}$ 方向の集中荷重として表す. また，その作用点 $\mathrm{A}$ の位置を $\theta=\angle \mathrm{AO}_{\mathrm{w}} \mathrm{C}$ で表すことにする， $\theta$ は 1 ステップの駆 動角度で, ステップ角と呼ぶ. $T_{g}$ はワブルリングの自転をと めるトルクで, ワブルリングとワブルジェネレータ間の接着 または摩擦により生ずる.

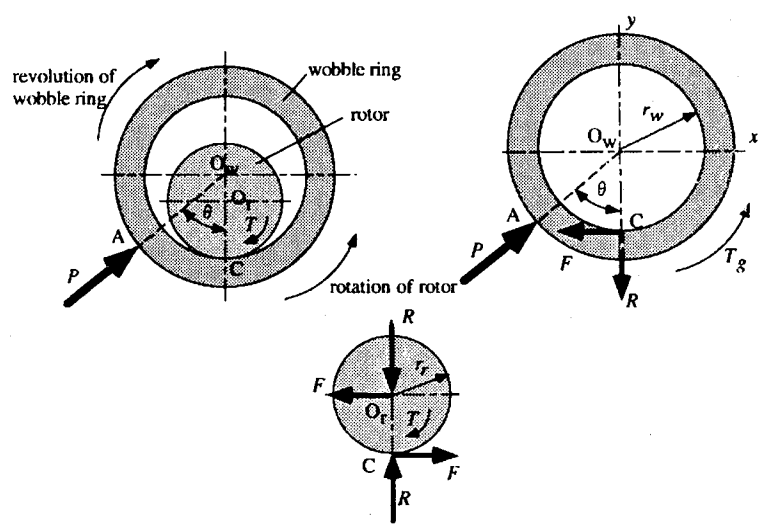

Fig.5 Static analysis of pneumatic wobble motor

ワブルジェネレータ内の圧力室加圧によって生ずる力 $P$ は 圧力室加圧によって生ずる力の $\mathrm{AO}_{\mathrm{w}}$ 方向の成分であるから, 次式となる.

$P=2 r_{g} t p \sin \left(\frac{n \phi}{2}\right)$

ただし， $n, r_{g}, \phi, t, p$ はそれぞれ，加圧している圧力室の 数, ワブルジェネレータ圧力室の半径，一つの圧力室がワブ ルリングの中心 $\mathrm{O}_{\mathrm{w}}$ に対して占める中心角, ワブルジェネレー タの圧力室の軸方向の厚み，加圧空気圧である．また，ワブ ルジェネレータの弾性変形に要する力は空気圧よって生ずる 力に比べて十分に小さいので無視した.

一方，ロータには，負荷トルク $T$ と，歯車のかみあいによ って生ずる力（接線方向成分 $F$ と径方向成分 $R$ で表す）が働 く.ロータはベアリングによって点 $\mathrm{O}_{\mathrm{w}}$ 回りに回転支持されて いるので，上記 $F, R$ はベアリングにより受けられる.

ロータの負荷トルク $T$ は次式で表される.

$T=r_{r} F$
ただし $r_{r}$ はロータの外歯車のピッチ円半径である．歯車の圧 力角 $\alpha$ とすると次式が成り立つ.

$R=F \tan \alpha$

空圧ワブルモータでは，ロータに過大な負荷トルクがかか ると，接触点 $\mathrm{C}$ においてロータの歯がワブルリングの歯を乗 り越える現象が生じることがある。これをラチェッティング （歯飛び）現象と呼ぶ.

モータが動作するには,

（1） Pによって生ずるロータのトルクが負荷トルクよりも大 きいこと,

(2) ラチェッティングトルクが生じないこと,

の二つの条件を満足する必要がある.

上記二つの条件は，それぞれ図の X 方向，Y方向の力のバラ ンス式に対応しており，以下のように記述できる。

すなわち，上記(1)の条件として，

$F<P \sin \theta$

ラチェッティングトルクが生じない条件(2)は,

$R<P \cos \theta$

式(5)，(6)を用いて書き換えると，それぞれ，以下となる.

$T<r_{r} P \sin \theta$.

$T<r_{r} P \cos \theta / \tan \alpha$

さらに式(4)を用いて書き換えると，それぞれ，以下となる. $T<2 r_{r} r_{g} t \sin \left(\frac{n \phi}{2}\right) \sin \theta \cdot p$

$T<2 r_{r} r_{g} t \sin \left(\frac{n \phi}{2}\right) \frac{\cos \theta}{\tan \alpha} \cdot p$

式(11)かつ式(12)を満たすものが空压ワブルモータのトルク となる。

\section{4. 機構設計と制御}

\section{1 設計}

今回試作した 3 室マイクロ空圧ワブルモータは, 直径 $6 \mathrm{~mm}$, 長さ $5.6 \mathrm{~mm}$, シャフト径 $1 \mathrm{~mm}$, 質量 $0.46 \mathrm{~g}$ である.

ワブルリングの歯数は 36 , ロータの歯数は 35 で, モジュ 一ルは 0.067 , 圧力角は $60 \mathrm{deg}$ である. 歯車の歯形はインボリ ユート歯形を基本とした。 また $r_{r}=1.172 \mathrm{~mm}, n=1, r_{g}=2 \mathrm{~mm}, \phi$ $=99.1^{\circ}, t=2.8 \mathrm{~mm}$ とした.

ワブルジェネレータはシリコーンゴムを使用した. 硬度 28 , 引張強さ $4.0 \mathrm{MPa}$ ，切断時伸び $450 \%$ の透明のものである。

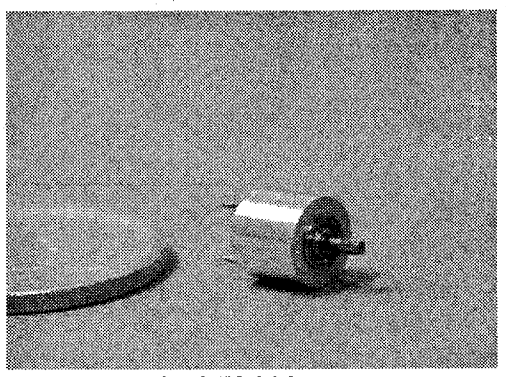

Fig.6 Wobble motor 


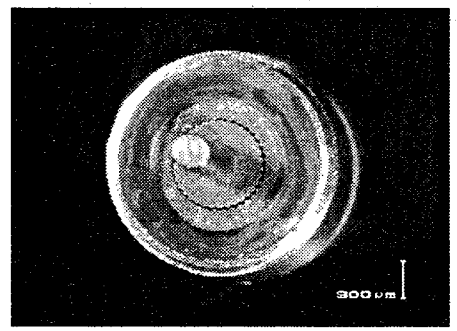

Fig.7 Wobble motor mechanism removing the cover

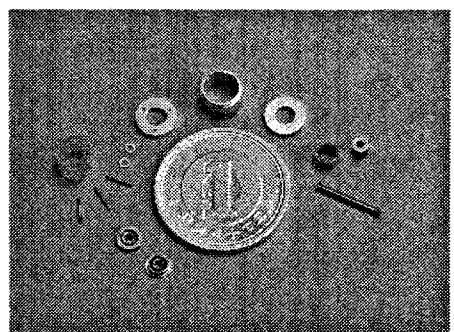

Fig.8 All parts of wobble motor

\section{2 制御}

ハーフピッチ駆動と呼ばれる加圧パターンを図 9 に示す. このとき 1 ステップは $\theta / 2$ となる.つまり 1 ステップは $60^{\circ}$ である. 図 9 で 1 は加圧状態を 0 は大気圧への開放状態を示 している. 圧力制御には電磁ソレノイド弁を用い，今回はこ のパターンで試験を実施した。

$$
\text { CH. } \quad 1 \quad 2 \quad 3
$$

$$
\text { Time } \downarrow \begin{array}{ccc}
1 & 0 & 0 \\
1 & 1 & 0 \\
0 & 1 & 0 \\
0 & 1 & 1 \\
0 & 0 & 1 \\
1 & 0 & 1
\end{array}
$$

Fig.9 Driving pattern

\section{5. 評価実験}

開発したモータの出力に直接負荷を掛けて, 特性実験を行 った。 $0.4 \mathrm{MPa}$ のとき，無負荷時の最大速度 $57 \mathrm{rpm}$, ラチェッ ティングトルク $0.6 \mathrm{mNm}$, 減速比 $1 / 35$, 分解能 $210 \mathrm{step} / \mathrm{rev}$.を 確認した.このときの理論最大トルクは, $1.15 \mathrm{mNm}$ 末満とな った. 図 10 に回転数 $10 \mathrm{rpm}$ 時の空気圧と最大トルクの関係に ついて，理論トルクと実測トルクを併せて示す.

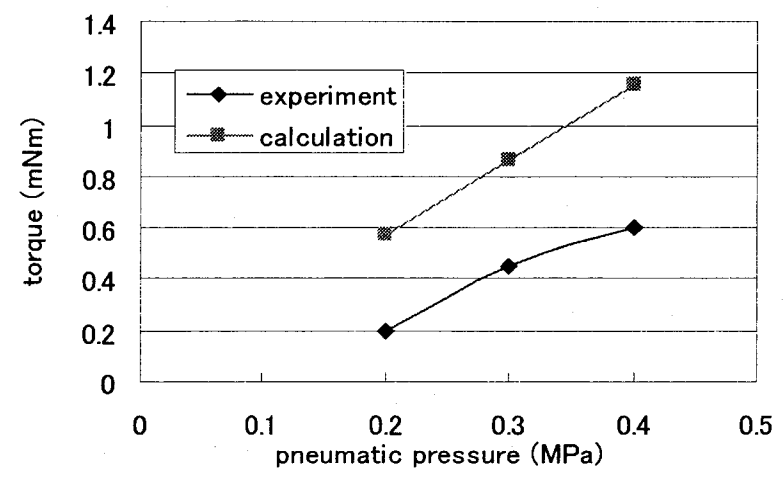

Fig.10 Relation between pneumatic pressure and torque at $10 \mathrm{rpm}$
図 10 より，実測トルクは理論トルクの半分ほどしかない。 これは想定よりもラチェッティングが生じやすいためと考え られる.ラチェッティングトルクは歯車の圧力角に大きく影 響を受ける. 特に微細加工による歯車設計のため, 小さな誤 差が大きく影響している可能性がある。

\section{6. 結言}

微細加工技術とゴムの微細成型の工夫により圧力室 3 室 $\phi$ $6 \mathrm{~mm}$ のイクロ空圧ワブルモータを開発した。このモータの 特徴として以下が挙げられる。

(1) 小型, 軽量, 簡単構造,

(2) 高トルク,

(3) 高分解能のステッピング動作,

（4）ラチェッティングによる過負荷防止機能.

実測トルクは理論トルクの半分ほどしかなく，これは想定 よりもラチェッティングが生じやすいためと考えられる. 歯 車の圧力角が大きく影響していると考えられるため, 今後改 善を進める.

今回開発したモータと，市販のほぼ同外径の典型的な電磁 モータの比較を表 1 に示す. マイクロ空圧ワブルモータは, 従来の電磁モータに比べ, 軸方向に極端に短い構成が可能で あることがわかる。

Table.1 Comparison of a pneumatic wobble motor with an electromagnetic motor

\begin{tabular}{|l|l|l|l|}
\hline & $\begin{array}{l}\text { Size } \\
(\mathrm{mm})\end{array}$ & $\begin{array}{l}\text { Torque } \\
(\mathrm{mNm})\end{array}$ & $\begin{array}{l}\text { Torque/volume } \\
\left(\mathrm{Nm} / \mathrm{mm}^{3}\right)\end{array}$ \\
\hline $\begin{array}{l}\text { micro pneumatic } \\
\text { wobble motor }\end{array}$ & $\phi 6 \times 5.6$ & 0.6 & 3.8 \\
\hline $\begin{array}{l}\text { electromagnetic motor } \\
\text { (no reduction gear) }\end{array}$ & $\phi 6 \times 15.6$ & 0.21 & 0.49 \\
\hline $\begin{array}{l}\text { electromagnetic motor } \\
(1 / 221 \text { reduction ratio) }\end{array}$ & $\phi 6 \times 30.3$ & 30 & 35 \\
\hline
\end{tabular}

\section{参考文献}

[1] 鈴森康一・堀光平空圧ワブルモータの研究, 日本機械学 会論文集(C 編)(1998-6)，236-241

[2] 都甲良平 - 鈴森康一 - 神田岳文 - 山田嘉昭, $\phi 6.5 \mathrm{~mm}$ マ イクロ空圧ワブルモータの開発, 第 46 回自動制御連合講演会 (2003), 22 